[Agr. Biol. Chem., Vol. 32, No. 5, p. 593 598, 1968]

\title{
Composition of Peel Oil from Citrus Unshu ${ }^{\dagger}$
}

\author{
By Tei Yamanishi, Akio Kobayashi, Yasuko Mikumo, Yoko Nakasone, \\ Masae Kita and Satohiko Hattori* \\ Laboratory of Food Chemistry, Ochanomizu University \\ *Takasago Perfumery Co., Lid. \\ Received October 17, 1967
}

\begin{abstract}
Constituents of aroma of peel oil (both oleoresin and cold-pressed oil) from Citrus Unshu were isolated by column chromatography and gas chromatography (GLC), and identified mostly by infrared (IR), partially by mass (MS) and nuclear magnetic resonance (NMR) spectroscopy.

One hundred and seven compounds were found in the oil and among them, four sesquiterpene hydrocarbons, five acetates, five carbonyls and five alcohols were identified as a main constituents which contributed to difference in flavor from other citrus peel oils. Characteristics of aroma of C. Unshu was discussed on the basis of quantitative analysis.
\end{abstract}

Constituents of various citrus peel oils have been investigated by many researches. ${ }^{1251}$

Citrus Unshu, produced in the limited area (only in Japan and China), has some characteristic aroma.

The present paper describes a procedure for isolation of the aroma components of peel oil from C. Unshu followed by identification with the use of IR, MS, and NMR and or thin layer chromatography (TLC) and elementary analysis.

Combination of silica-gel column chromatography and GLC was particularly effective to get a complete separation and also to presume

$\dagger$ Presented at the Annual Meeting of the Kanto Branch of the Agricultural Chemical Society of Japan, held on October 6th (1967).

1) R. W. Wolford, J. A. Attaway, G. E. Alberding and C. D. Atkins, J. Food Sci., 28, 320 (1963).

2) E. Kugler and E. sz. Kovats, Helu., 96, 1480 (1963).

3) G. L. K. Hunter and M. G. Moshonas, Anal. Chem., 37, 378 (1965); J. Food Sci., 31, 167 (1966); G. L. K. Hunter and W. B. Brogden, Jr., ibid., 30, 383 (1965)

4) Y. Ohta and Y. Hirose, Agr. Biol. Chem., 30, 1196 (1966)

5) R. Teranishi, R. E. Lundin, W. H. Mc Fadden, T. M. Mon, T. H. Schultz, L. L. Stevens and J. Wasserman, J. Agr. Food Chem., 14, 447 (1966). a class of the compound from a position on the diagram obtained by plotting the fraction number of silica-gel column chromatography against the peak number of GLC.

\section{EXPERIMENTAL AND RESULT}

\section{Material}

1) Peel oleoresin. Peel of C. Unshu, picked at Kanagawa Prefecture during 1964 66 season, was extracted with acetone after drying and powdering. From the extract, excellent aroma-containing oleoresin was obtained by distilling off acetonc under reduced pressure, below $40^{\circ} \mathrm{C}$. Oleoresin was obtained in about $1.50^{\circ}$ yield of dried peel.

2) Cold-pressed peel oil. Peel from the same C. Unshu was used for preparation of coldpressed oil.

\section{Apparatus}

Gas chromatographic separations were carried out in a Shimadzu Model IC containing a $3 \mathrm{~mm}$ id. by $185 \mathrm{~cm}$ stainless $U$ tube packed with $23 \%$ Ucon $50 \mathrm{HB} 270 \mathrm{X}$ on Shimalite W $(60 / 80 \mathrm{mesh})$. The oven temperature was $150^{\circ} \mathrm{C}$ or $160^{\circ} \mathrm{C}$, isothermal except the case of carbonyl fraction in which programming from 
$70^{\circ} \mathrm{C}$ to $150^{\circ} \mathrm{C}$ (rate $2^{\circ} \mathrm{C}$ per $\min$ ) was employed. Helium flow rate was $20 \mathrm{ml}$ to $30 \mathrm{ml}$ per min. The materials represented by the peaks were collected into cold capillary tube immersed in a dry ice-acetone mixture for identification.

Column chromatography was accomplished in a $3 \mathrm{~cm}$ od. by $50 \mathrm{~cm}$ column containing silica-gel. Elution was carried out with $n$ - hexane, mixtures of ether and $n$-hexane of several kinds of proportion and methanol as shown in Fig. 4.

Infrared spectra were obtained using a Japan Spectroscopic Co. Model IR-S. MS and NMR were obtained with a Hitachi Ltd. RMU-6E and Model JNM-C-60 of a Japan Electron Optics Laboratory Co. Ltd. respectively.

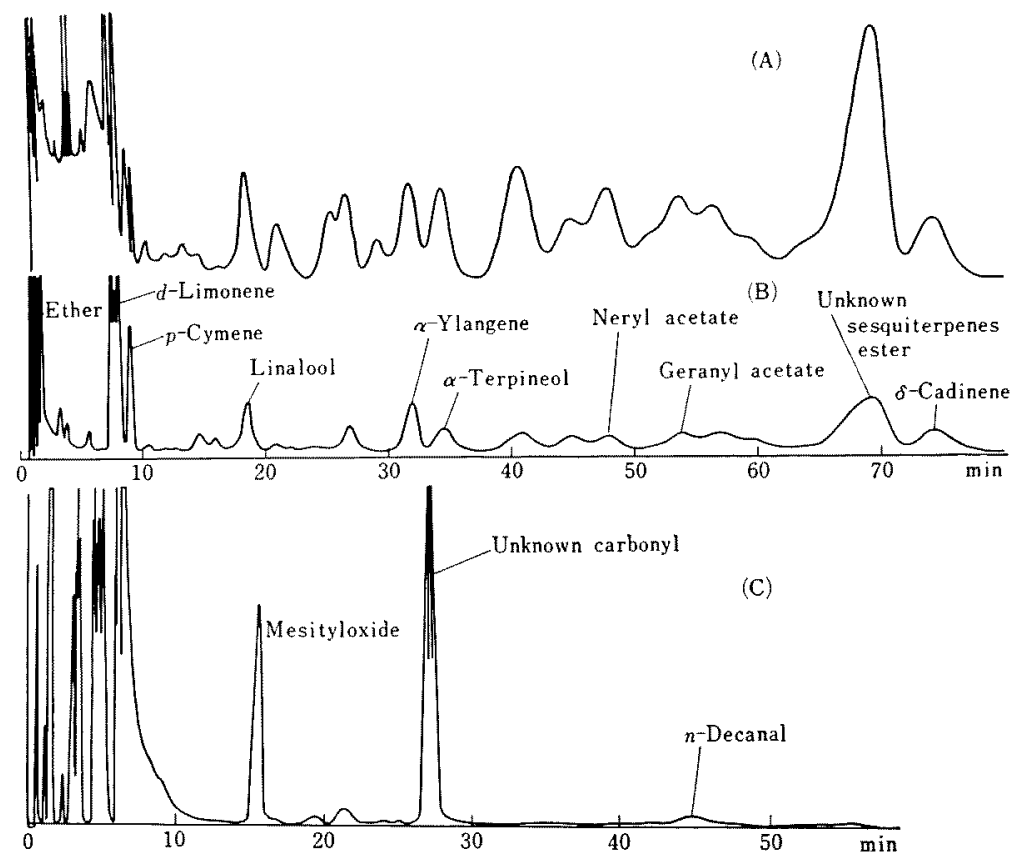

FIG. 1. Gas Chromatograms of the Essential Oil from Peel Oleoresin of C. Unshu and the Carbonyl and Non-carbonyl Fractions.
(A) Whole essential oil
(B) Non-carbonyl fraction
Column Temp:
(C) Carbonyl fraction
(A) $150^{\circ} \mathrm{C}$
(B) Isothermal
(C) $70^{\circ} \mathrm{C} \sim 150^{\circ} \mathrm{C}$ programming rate $2^{\circ} \mathrm{C} / \mathrm{min}$

Tabe I. Fractionation of Cold-Pressed Peel OIl by Vacuum Distillation

\begin{tabular}{|c|c|c|c|c|}
\hline $\begin{array}{l}\text { Fraction } \\
\text { No. }\end{array}$ & $\begin{array}{l}\text { Distilled } \\
\text { temperature }\end{array}$ & Yield & Color & Aroma \\
\hline 1 & $\sim 67^{\circ} \mathrm{C} / 7 \mathrm{~mm}$ & 91.00 & Pale yellow & $\begin{array}{l}\text { Limonene like, somewhat acidic and } \\
\text { bitter odor }\end{array}$ \\
\hline 2 & $35 \sim 52 \mathrm{C} / 3 \mathrm{~mm}$ & 2.1 & Pale yellow & Limonene like \\
\hline 3 & $67 \sim 79^{\circ} \mathrm{C} / 3 \mathrm{~mm}$ & 0.5 & Yellow & Sweet orange \\
\hline 4 & $77 \sim 87^{\circ} \mathrm{C} / 3 \mathrm{~mm}$ & 0.7 & Greenish yellow & Sweet and heavy aroma of Citrus Unshu \\
\hline 5 & Residue & 5.7 & Dark brown & Woody and resine like \\
\hline
\end{tabular}




\section{Separation and analysis}

The essential oil was prepared from the oleoresin by steam distillation under the reduced pressure by the same method as used in the previous work on tea flavor, ${ }^{6 /}$ and analyzed as follows: A portion of the essential oil was separated into acidic, basic and neutral fractions by routine procedure and examined by GLC. The aroma and the chromatogram of neutral fraction were very similar to those of original essential oil.
Therefore, without removing acidic and basic fractions, major portion was directly separated into carbonyl and non-carbonyl fractions by Girard-T reagent and subjected to GLC. Chromatograms of the essential oil and these two fractions are shown in Fig. 1. IR spectra showed several single peaks due to more than one compound.

As for cold-pressed oil, other procedure was employed. First, cold-pressed oil was subjected to a fractional vacuum distillation under
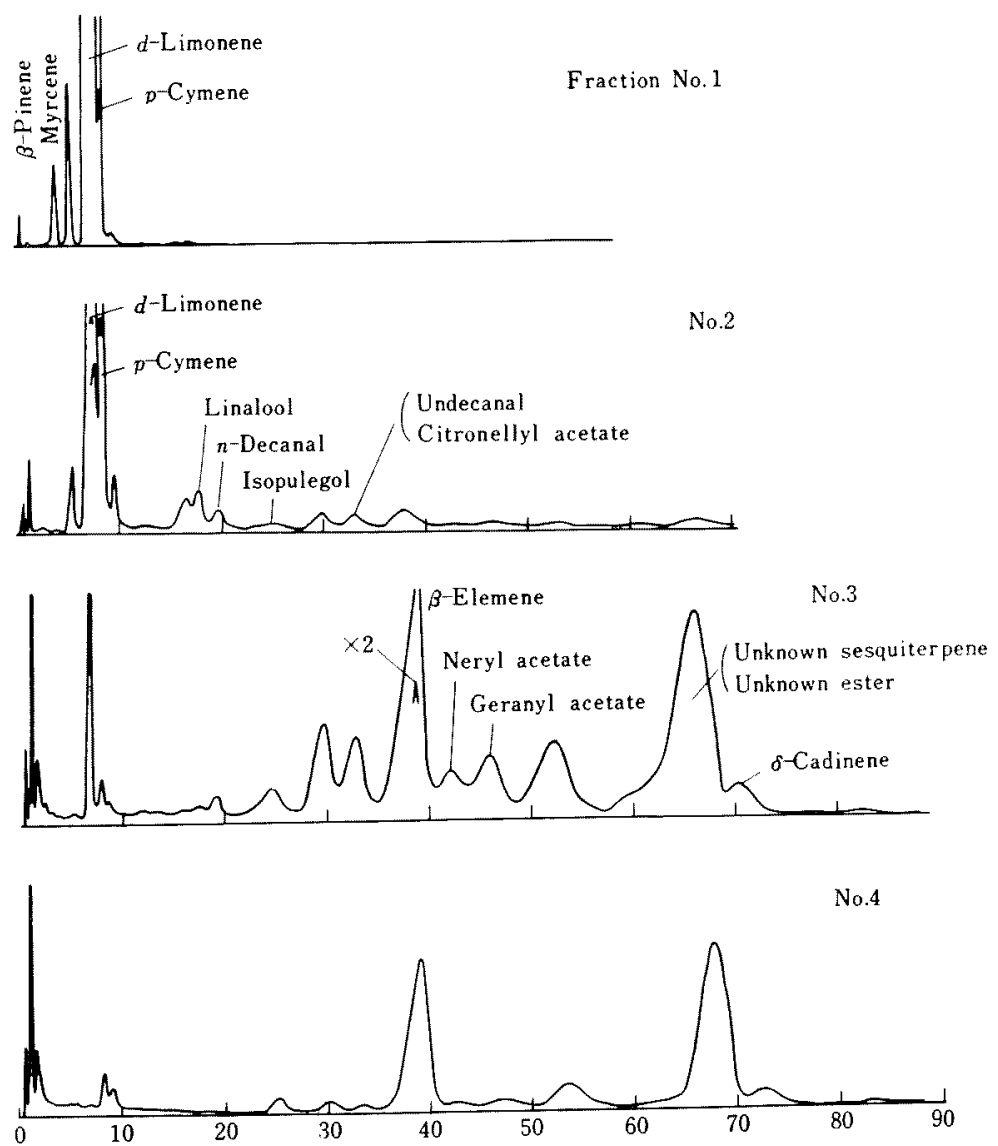

Fig. 2. Gas Chromatograms of the Four Fractions of Cold-pressed Peel Oil from C. Unshu.

6) T. Yamanishi, T. Kiribuchi, M. Sakai, N. Fujita, Y. Ikeda and K. Sasa, Agr. Biol. Chem., 27, 193 (1963). 
the stream of nitrogen and separated into five fractions as shown in Table I. GLC of the four fractions are in Fig. 2. Fraction No. 1 consisted of about $96 \%$ of $d$-limonene, $2.5 \%$ of $p$-cymene, $1 \%$ of $\beta$-pinene and myrcene. Fraction No. 2 contained $62 . \%$ of $d$-limonene and $20 \%$ of $p$-cymene.

Since the main substances which contributed to the characteristic aroma of C. Unshu seemed to be contained in Fraction No. 3 and No. 4 , the fractions were subjected to silica-gel column chromatography and separated into fifty fractions. Each fraction was evaporated under reduced pressure at temperature below $50^{\circ} \mathrm{C}$ to remove the solvent and analysed by GLC. After analysis, each fraction was further separated by GLC. IR spectra of main components as shown in Fig. 3 were quite identical with that of authentic compound (gas chromatographically pure). Besides IR, some peaks were identified by TLC, MS and NMR. Approximate quantitative data were also obtained by calculating of the yield of each fraction and peak area of GLC. The results are summarized in Table II.

To look over the aroma pattern, the authors obtained the diagram by plotting the fraction number of column chromatography against the peak number of GLC (numbered in the order of retention time) as shown in Fig. 4. Thus, one hundred and seven components in the peel oil were recognized on the diagram.

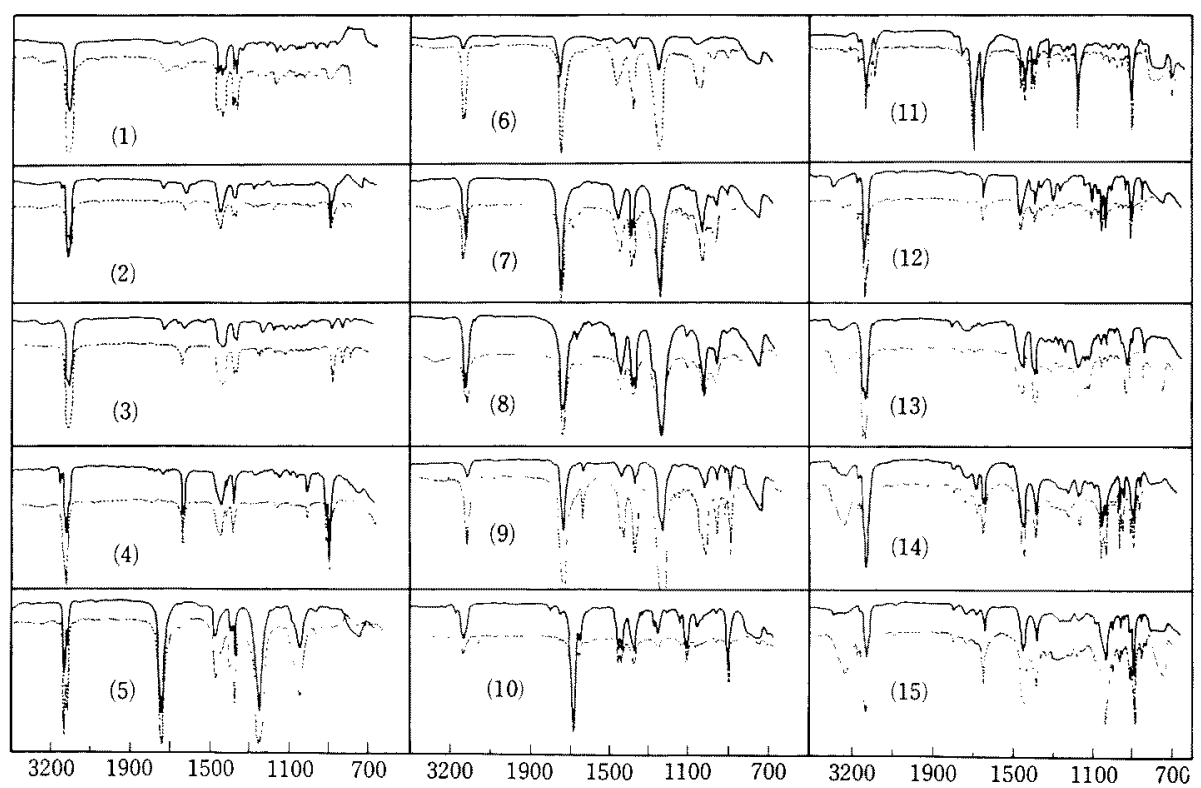

FIG. 3. Infrared Spectra of Main Components in Peel Oil from C. Unshu and of the Authentic Compounds.
(1) Component No. 3 $\alpha$-Ylangene
(2) Component No. 9 Caryophyllene
(3) Component No, 13 $\delta$-Cadinene
(4) Component No. 15 $\hat{\beta}$-Elemene
(5) Component No. 45 n-Octyl Acetate
(6) Component No. 49 Citronellyl Acetate
(7) Component No. 51 Neryl Acetate
(8) Component No. 52 Geranyl Acetate
(9) Component No. 69 Perillyl Acetate
(10) Component No. 91 Carvone
(11) Component No. 92 Perillaldehyde
(12) Component No. 97 Isopulegol

(13) Component No. 103 $\alpha$-Terpineol

(14) Component No. 106 cis-Carveol

(15) Component No. 109 trans-Carveol 


\section{DISCUSSION}

The characteristic aroma of C. Unshu seemed to be chiefly due to the larger contents of $\beta$-elemene and acetates of four terpene alcohols after comparing the composition with those of other citrus peel oils reported by other workers. ${ }^{1 \sim 51}$

There were two important components, i.e. an aldehyde and an ester, which seemed to contribute to the characteristic aroma of $\mathrm{C}$.
Unshu, still remained unknown because of the difficulty to obtain an enough amount of samples for the elucidation.

Aroma of peel oleoresin was superior to that of cold-pressed oil. One reason for this fact seemed to depend on the higher concentration of oxygenated compounds in peel oleoresin than in cold-pressed oil.

Further investigation is now in progress on both identification of the unknowns and eluci-

Table II. Identification and Quantitative Value of the Aroma Constituents of Peel Oll from Citrus Unshu

\begin{tabular}{|c|c|c|c|c|c|c|}
\hline $\begin{array}{c}\text { Silica } \\
\text { column } \\
\text { chromato. } \\
\text { Fraction } \\
\text { No. }\end{array}$ & $\begin{array}{l}\text { GLC } \\
\text { Peak } \\
\text { No. }\end{array}$ & $\begin{array}{l}\text { No. on } \\
\text { diagram }\end{array}$ & Costituent & $\begin{array}{l}\text { Method of } \\
\text { identification } \\
\text { besides GLC }\end{array}$ & $\begin{array}{l}\text { Cold-pressed } \\
\text { oil wt of } \\
\text { excluding } \\
\text { monoterpene } \\
\text { hydrocarbon }\end{array}$ & $\begin{array}{c}\text { Oleoresin } \\
\text { peak area } \\
0 \\
\text { excluded } \\
\text { limonene }\end{array}$ \\
\hline 2 & 15 & 3 & $d$-Ylangene & TLC, IR, MS & 6.0 & 6.3 \\
\hline 3 & 1 & 6 & $d$-Limonene & IR & $(\mathrm{ca}, 94)$ & - \\
\hline$" \prime$ & 2 & 7 & $p$-Cymene & IR & $(\mathrm{ca}, 2.8)$ & - \\
\hline$"$ & 18 & 9 & Caryophyllene & IR & 2.8 & $5.6 / 3^{*}$ \\
\hline$"$ & 29 & 13 & $\delta$-Cadinene & $E A$, "a) IR, MS & 5.0 & 8.9 \\
\hline 4 & 17 & 15 & $\beta$-Elemene & EA, IR, MS, NMR & R $\quad 24.6$ & 11.9 \\
\hline 29 & 8 & 45 & n-Octyl acetate & IR & 1.1 & $5.0 / 2^{*}$ \\
\hline$"$ & 9 & 46 & $n$-Decanal & TLC $(2,4-D N P)$, IR & 5.0 & 4.0 \\
\hline " & 17 & 49 & Gitronellyl acetate & IR & 4.1 & 6.3 \\
\hline$" \prime$ & 19 & 50 & Terpinyl acetate & IR & 1.6 & $5.6 / 3 *$ \\
\hline$" \prime$ & 21 & 51 & Neryl acetate & IR & 3.0 & 9.6 \\
\hline$"$ & 23 & 52 & Geranyl acetate & IR & 4.0 & 7.3 \\
\hline 33 & 17 & 56 & Undecanal & $\mathrm{TLC}(2,4-\mathrm{DNP})$ & 0.4 & - \\
\hline 36 & 25 & 59 & Dodecanal & $\operatorname{TLC}(2,4-\mathrm{DNP})$ & 0.5 & - \\
\hline 40 & 35 & 69 & Perillyl acetate & IR & 0.3 & - \\
\hline 46 & 19 & 91 & Carvone & IR & 0.2 & $5.3 / 3 *$ \\
\hline$n$ & 33 & 92 & Perillaldehyde & IR & 0.5 & - \\
\hline 49 & 8 & 96 & Linalool & IR & 2.2 & $5.0 / 2 *$ \\
\hline$"$ & 11 & 97 & Isopulegol & IR & 1.6 & - \\
\hline 50 & 16 & 103 & $\alpha$-Terpineol & IR & 1.6 & \\
\hline$"$ & 24 & 106 & cis-Carveol & IR & 1.4 & \\
\hline$" \prime$ & 26 & 107 & trans-Carveol & IR & 0.1 & \\
\hline 5 & 28 & 17 & a Sesquiterpene & IR & 7.2 & 9.9 \\
\hline 29 & 17 & 48 & $\begin{array}{l}\text { an Aldehyde } \\
\text { (characteristic aroma of } \\
\text { sweet orange) }\end{array}$ & IR, NMR & 3.0 & \\
\hline 31 & 32 & 53 & an Ester & IR & 0.8 & 0.8 \\
\hline 33 & 14 & 54 & $\begin{array}{l}\text { an Ester } \\
\text { (characteristic aroma of } \\
\text { sweet peach) }\end{array}$ & IR & 1.3 & 0.8 \\
\hline
\end{tabular}

Numbers in ( ) present Wto in whole peel oil.

Numbers of $*$ mark is that of mixed components in single peak. a) EA means elementary analysis. 


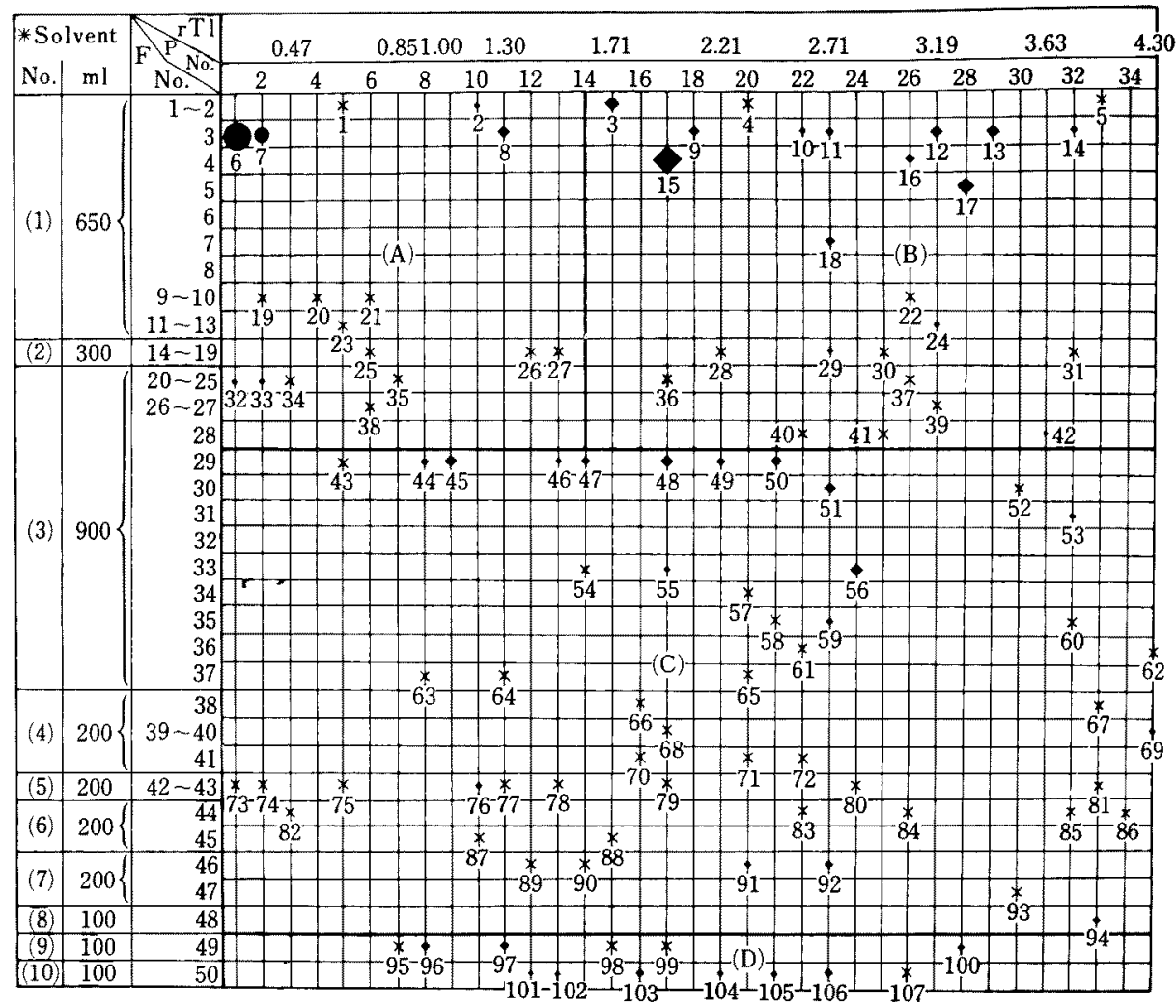

FIG. 4. Diagram of the Aroma Composition of Peel Oil from C. Unshu. * Solvent

No.
1. $n$-Hexane
2. $10 \%$ Ether added
n-Hexane
3. $2 \%$ Ether
4. $3 \%$
5. $4 \%$
6. $6 \%$
7. $8 \%$
8. $12 \%$
9. $20 \%$
10. Methanol

No.

1. n-Hexane

10 Ether added

6.60

7. $80^{\circ}$

9. $20 \%$

10. Methano

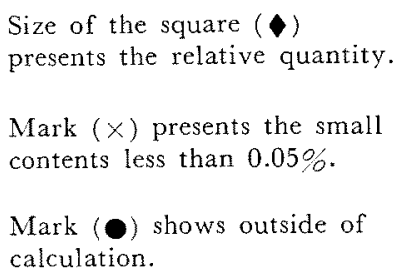

(B) Area of sesquiterpene hydrocarbone

(C) Area of carbonyls and Esters

(D) Area of Alcohols dation of the reason of aroma difference between oleoesin and cold-pressed oil.

Acknowledgements. Elementary analyses were determined by Mr. K. Furuhashi of
Tokyo University of Education, Mass spectra were obtained by the help of Dr. H. Sato of Hitachi Ltd. The authors with to express their gratitude to them. 